This is the version of the article/chapter accepted for publication in Critical African Studies published by Taylor and Francis: https://doi.org/10.1080/21681392.2018.1463143

Accepted version downloaded from SOAS Research Online: http://eprints.soas.ac.uk/32041

\title{
Black November (2012) and its social change potential: Reactions from the audience
}

\author{
Añulika Agina \\ Pan-Atlantic University, Lagos, Nigeria
}

\begin{abstract}
This article examines, through multiple film screenings and Focus Group Discussions, the potential of Black November (2012) to initiate social change in the 20th anniversary of Ken Saro-Wiwa's death. Current research on African film is skewed towards broad representations of urban and rural lives, thus making the reception of indigenous popular films an understudied area. Virtually absent in African film scholarship is the reception of the films as agents of potential social change. The nexus between popular films and social change is examined here in the aftermath of failed formalized processes of conflict resolution. Recent popular film reception studies (Krings and Okome, 2013) have transnational foci, which focus on African emigrants' conditions of life in foreign localities. The paper, therefore, evaluates the impact of popular films on viewers and how they interpret the film as being instrumental in changing oppressive situations in the Niger Delta. It deploys the theory that the arts function as peace-builders and tools for social change among conflicting parties (Shank \& Schirch, 2008) in the light of the Niger Delta struggles, particularly those championed by Ken Saro-Wiwa, which are revisited two decades after his internationallycondemned murder. Findings include that Black November cannot function in isolation to produce social change but must work within a broad framework of strategies serving the same goal.
\end{abstract}

Keywords: Niger Delta, Ken Saro-Wiwa, reception, audience, social change, Nigerian film

\section{Introduction}

There has been a growth in the production of African popular films with Nigeria leading this growth. From the year 2000, the thematic concerns of Nigerian films have shifted significantly from voodoo, illegal wealth and women's plight to an upsurge in romantic comedies, and to political issues, such as governance, war and oil exploration (Haynes, 2006; Okoye, 2007; Agina, 2013). The number of films representing the Niger Delta conflict (e.g. Black November (2012), Dir Jeta Amata) has not grown at the same pace, although the industry has produced several activist films and political critiques. There have also been 
significant developments in the film industry and its scholarship - with monographs being dedicated to Nollywood celebrities (Tsika, 2015) or newer forms of organisation and distribution (Miller, 2016). What seems to remain unchanged is the dearth of reception studies of Nigerian and African screen media (Krings, 2010) or even the assessment of the potential 'impact' of films among the people whose lives and culture they represent. This paper attempts to contribute to the reception discourse by examining audience reactions to one political critique about the Niger Delta.

From the mid 1950s, the Nigerian State discovered oil in commercial quantities in the southern parts of the country (known as the Niger Delta region) and began the exportation of crude oil. With the alliance of Shell Petroleum and the Nigerian government, the proceeds of the oil business constituted the bulk of government revenue. Oil exploration activities had devastating effects on the land and people of the Niger Delta. One of the worse-hit areas to date is Ogoniland. William Boyd, British writer and close friend of a leading Nigerian writer and minority rights' activist, Ken Saro-Wiwa, puts it aptly, "What was once a placid rural community of prosperous farmers and fishermen is now an ecological waste land reeking of sulphur, its creeks and water holes poisoned by indiscriminate oil spillage and ghoulishly lit at night by the orange flames of gas flares" (p. x). One of numerous "massively dispossessed" (Nixon, 2011) communities, Ogoni is a minor tribe of less than a million people who live in a small area of the fertile Niger Delta. Naturally, the people of Ogoni protested the land and air pollution through several initiatives, particularly the formation of the Movement for the Survival of the Ogoni People (MOSOP) in 1990. Instrumental to the establishment of MOSOP and its first leader was Saro-Wiwa, who led his people in speaking truth to the Shell-Nigerian government alliance, and seeking restorative measures to the plight of Ogoni people at the national and international levels. Both Shell and the government rejected MOSOP's pleas and in 1994, the military government led by General Abacha arrested SaroWiwa on trumped-up charges and executed him by hanging in November 1995. This inspired the title of the film under investigation, Black November.

Between 1995 and 2015, the Niger Delta has been (and still is) synonymous to human rights violations of the most severe kind, attacks and counteracts between successive governments and militant groups, and even a breakdown of oil exploration with its attendant loss of revenue. Artists, including Nollywood filmmakers, have found in the conflict generated in the region a veritable source of expression (Agina, 2013). The film, Black November is a social document that responds to the Niger Delta crisis. The article focuses on one film, Black November, because it is the most recent depiction of a Ken Saro-Wiwa story. To be clear, the film does not directly represent Saro-Wiwa as himself, but uses a female character to embody the environmental activist killed in 1995. Directed by Jeta Amata, a Nigerian emigrant to the United States, on a budget of about \$7M, and set in Nigeria and the US, the film assembles a cast of Nollywood and Hollywood actors. Amata believed himself to be an activist in directing the film, likening his motivations and objectives to those of the militants when he said "I am involved in the same cause of the militants but without weapons" (personal communication, Jeta Amata). 
Black November portrays a group of activists, who kidnap the CEO, Tom Hudson, (Mickey Rourke) of Western Oil in the US and keep him hostage in a tunnel until the release of the film's protagonist, Ebiere Perema (Mbong Amata), who is about to be hanged in Warri. Hudson's crime is his company's activities, which leave parts of the Delta polluted due to frequent and unchecked oil leakages. After an oil pipeline explosion that kills Ebiere's family and several hundred indigenes, efforts by surviving locals to seek redress pit the community against the government and Western Oil. The latter negotiates a compensation scheme for the indigenes, but avaricious community chiefs connive with the liaison officer at Western Oil and government officials to siphon the money meant to repair the community's damages. What the filmmaker attempted to portray in the film is what Nixon (2011) eloquently attests to

Shell, Chevron, and successive Nigerian regimes have siphoned $\$ 30$ billion worth of oil from beneath Ogoni earth. Yet the locals still find themselves lacking a hospital, electricity, piped water, basic roads, housing, and schools. The community has found itself, in the fullest sense of the word, utterly undermined (p. 108)

The resulting tensions between the indigenes, the government - who moves in, questionably, to maintain order - and the oil company escalate, leading to the death of an innocent chief, who decried the diversion of funds. The deceased's son uses information obtained from his father before his death to track the murderers. While Ebiere is making plans to hand the culprits to the police, her companions thrust them into a car and set it on fire in a move that is reminiscent of one of the trumped-up charges against Saro-Wiwa in 1995. Upon arrest and trial, Ebiere perjures herself in court in order to release her fellow protesters. The film ends tragically with her being hanged which, once again, evokes the hanging of Saro-Wiwa. The overarching question this paper interrogates is the potential impact of Black November through reception analysis, thus making it an audience study. 'Potential impact' is used here to refer to the possibilities of social change that a film is capable of achieving when viewed by certain strategically-elected decision makers, any of those represented in the film and the viewing populace. It is necessary to tread with caution in claiming the extent to which films make an impact, as that impact can take a long time to manifest, even before it can be measured by researchers. It can also be presumptuous to claim how much impact a film has made, since there is an interplay of factors responsible for the construction of meaning among audiences, hence the qualifying term, 'potential.' Four sub-questions are pertinent. When the figure of Ken Saro-Wiwa is fictionalised through the cinematic lens, do viewers find the representation satisfactory enough to elicit change? Does Black November have the potential to alter the status quo in the Niger Delta? What most powerful scene(s) would expedite action and result in societal change? What alternative circulation avenues do audiences envisage might create the potential impact?

In the ever-increasing output on African, and specifically Nollywood film scholarship, there seems to be a disquieting paucity of reception studies. This paper attempts to enter the reception discourse through the Black November narrative and the prevailing situations in the 
Niger Delta. The general theoretical formulations on reception by Barber (1997), Hall (1999) and Yousman (2013), as well as their specific application to African film offered by Okome (2007) and Okome and Krings (2013), are examined intentionally to situate this paper within the broader discourse of audience and reception studies. Because of the social change perspective from which Black November is interrogated, scholarly reflections on the arts as agents of social change in the works of Shank (2004), Lederach (2005) and Shank and Schirch (2008) also provide the context for study as contributing to conversations on film activism and social change.

Yousman's (2013) methodology on television audiences was adopted for this study in a semiethnographic fashion because it entailed screenings and discussions by people familiar with the issues represented. He showed TV representations of incarceration to ex-prisoners and held discussions on the screenings in a bid to establish how adequately TV shapes public opinion on crime and incarceration. Machor and Goldstein (2001) argue that "[E]thnographies of reception are conducted among specific sociocultural audiences to provide thick descriptions of the viewing...experience and the social and cultural conditions that constitute particular contexts of reception" (p. 205). As an interpretative investigatory tool for this study, ethnography allowed the researcher to act as a participant observer in order to gather textual data from groups of audiences at six different screenings between November 2015 and June 2016. Although the film was mostly screened in places where the audience would not normally gather to watch films (hence the term semi-ethnography), that is, in lecture theatres and a hotel meeting room (with one viewing happening in an informal conference location), the researcher's observation and interaction with viewers at all six screenings conferred an ethnographic property to the study. The screenings were followed by Focus Group Discussions (FGDs) with audiences who were invited by email specifically for the screenings. Of the eighty-one graduate students, journalists and lecturers who claimed familiarity with the Niger Delta conflict, a third of that number was too emotionally affected after viewing to contribute to the FGDs. Accidentally, there were more women than men among viewers in a two to one ratio. The average number per group was thirteen, which is an ideal one for FGDs. Each discussion lasted about 30 minutes. Some groups filled out a questionnaire with the same open-ended questions, which guided and kept the discussion within the scope of film and social change.

\section{Reception, art activism and social change}

Barber's (1997) reception analysis tends to focus on audiences and their readings of texts in historical and contemporary contexts in ways similar to Machor and Goldstein (2001)'s ethnography. Reception is always active and contextual, with multiple frames of reference at play and shaping the interpretive process. She affirms that "there are different ways of convening and of experiencing reception, whether collectively or in dispersal, which are deeply connected to the nature of social life of the age and place" (p. 347). This suggests that reception is a complex activity, which is creatively negotiated around the social realities of 
audiences. Barber sustains this argument throughout her reflections on how audiences receive texts by producing new texts and meaning on the basis of internally-generated and external social conditions. Although he referred particularly to television broadcasts, one of the leading proponents of reception analysis, Stuart Hall (1999), argues that "there is no necessary correspondence between encoding and decoding, the former can attempt to pre-fer but cannot prescribe or guarantee the latter, which has its own conditions of existence" (p. 515). It rejects the all powerful media theories and posits that media consumption has certain other identifiable features other than that intended by the producers of media content (Morley, 2001). Hall posits that production (encoding) and consumption (decoding) patterns are autonomous entities that possess "degrees of reciprocity" which permit communicative effectiveness. Encoding sets certain boundaries, within which decoding must occur. Decoding moments cannot be predetermined but must be constructed by an audience in ways different from another audience operating within other "frameworks of knowledge". Hall's four-stage theory of communication - production, circulation, consumption and reproduction - is not thoroughly accounted for by the encoding-decoding model since the former is a circuit while the latter is not. Yousman (2013) offers a critique of Hall's influential model when he states that

The appearance of the model as it is suggests that encoding is the starting point of the production of meaning, not just analytically but in practice, and this is not at all what Hall intended to suggest. Rather, meaning is being constantly produced and reproduced throughout (pp. 201-202).

Prior to Yousman, Machor and Goldstein (2001) note that reception occurs in a site marked by ideological and semiotic negotiation and contestation shot through with varying and at times contradictory meanings and significances generated by different audiences. And this process of meaning construction takes place at different stages of viewing as happened with the audiences interrogated for this study. As with Morley (2001), Schroder, Drotner, Kline and Murray (2003) point out that "reception research was characterised by a distinct predilection for the television medium and for the genres of news and serial fiction..." (p.108). But this has extended to other media, including fiction films, as evidenced by Staiger (2001) and Okome (2007). Barber (1997) opines that audiences "use media products to reflect on their own concerns" which enable them "make up their minds about things" (p. 357) thereby affirming that media represent audience aspirations. In line with Machor and Goldstein (2001), this reception study does not claim representativeness but "reflects the principle of being locally embedded within particular formations and social conditions" (pp. 208-209). To be clear, Black November is not representative of Nollywood films. In fact, the film differs from a typical Nollywood production in terms of its budget, which is considerably higher than the average, as well as its cast and crew. In addition to that, the context of reception of Black November reported below is not typical of film goers. Audiences were invited to screenings for research purposes; but the decision to participate in the post-screening discussions was entirely voluntary. 
Okome's (2007) engagement with the audience discourse takes off from Barber's work to gesture towards the multiple knowledge patterns by which audiences read Nollywood, thereby democratising the world views made possible in and through this form of popular media. Okome's focus on indigenous audiences and local sites of spectatorship contrasts with Krings and Okome's (2013) descriptions of Nollywood's spread in Europe and the Carribean. For both studies, viewers' reception of Nigerian films varies and is informed by their similarity to audiences' "local cultural formations" as well as their "alterity" (Krings \& Okome 2013 p. 4). They suggest that such similarities make it easy for Nigerians in the diaspora and other Africans to emulate behavioural and stylistic codes of conduct found in Nigerian films. In explicating how Africans interact with films coming from Nigeria, Krings and Okome go on to claim that the films are also seen as "transnational cultural anchor" ( $\mathrm{p}$. 5), that is, "as a site where migrant subjects meet the homeland in different ways" (ibid.). This is a point which Haynes (2013) also makes by identifying and labelling a genre of film made by Nigerians with collaboration from Europeans about longing for one's homeland while living elsewhere. The reception of Nigerian films in Africa has also led to the localisation of such films in certain other African countries like Tanzania, Kenya and Congo (Krings and Okome, 2013), or in co-productions with Nigerians, as Krings (2010) points out. Thus, it corroborates Barber's postulation of reception as production. In diverse ways, Nigerian films have made in-roads to other localities and have attempted to create social change in those contexts. These changes, arguably, represent the impact of Nigerian films when taken as a collective. But this study zooms into the kinds of potential impact that a specific film can make in its own context of production and consumption.

If social change in this paper is understood as conflict resolution, economic and infrastructural development and granting of privileges due to inhabitants of the Niger Delta, then it is important to examine how scholars have articulated the agency of films and the arts in general to promote social change. In the scholarship on art activism and social change, Shank (2004), Lederach (2005), and Shank and Schirch (2008) examine various ways by which involvement in the arts promotes peace among conflicting parties and changes situations of oppression and marginalisation to those of liberation and inclusivity. These art forms, which include painting, music, theatre and film, tend to possess a journalistic value by offering differing perspectives of the conflict. They also have an educational dimension wherein the pitfalls of violence and conflict are highlighted as a restorative goal, which allows the process of creating or consuming the art to engender change in a slow and identifiable manner. The latter is usually presented as an ideal situation, one which would restore the social order. It is in this light that Black November is examined and used to elicit audiences' reactions to the Niger Delta conflicts in a commemorative year. When Amata made the film, he had hoped to restore some kind of social order or initiate societal change albeit in a gradual process (personal communication, Jeta Amata). But given the prevailing narratives in the press on escalating tensions in Ogoni and its environs, does the film and others like it hold any of the potentials that Lederach and others propose? 
In his article on using syncretic theatre to promote active citizenship and activism in Zimbabwe, Chinyowa (2012) argues for an inclusive horizontal and bottom-up approach in which warring citizens deliberate and decide on theatrical performances together rather than having others' ideas imposed on them. In conformity to Shank (2004), Chinyowa suggests that "theatre-based conflict resolution can satisfy the need for critical objectivity by staging fictionalised stories that illuminate the specific conflicts affecting the community" (2012, p. 68). Through theatrical performances, critical community issues are brought to the fore and spectators are inspired to look beyond its entertainment value and thus realise that "the ultimate goal of forum theatre, therefore, is to encourage the autonomous expression of ideas, to set a process in motion, to stimulate a theatrical debate and to change spectators into 'spect-actors' who are capable of transforming oppression into liberation" (p. 75). Granted that every spectator is not always in a position of influence, which would make possible the sort of change Black November seeks, the fact of dramatising the conflict raises awareness that makes the need for change intensely visible.

Recalling how Nigerian films have specifically brought about change, McCall (2007) extends the arguments previously made by critics like Olatunde Lawuyi that generally, "Nollywood lacks the ideological mission that could make it relevant to political and social transformation in Africa" (p. 94). A more optimistic view is expressed by Abah (2009) who points out that Nigerian films only hold a potential for change, but such change is yet to be actualised. As such, Nollywood has arguably failed to attain an activist status even if some filmmakers regard themselves as activists. The thrust of Abah's argument, which is based on two specific examples, is that the films are able to influence social change because they are produced from the sheer effort of private entrepreneurs, not official, state-sponsored projects. Because the film industry is independent of the government, Abah argues, filmmakers are poised to be key drivers of social change in ways other than those attainable by various other indigenous state-controlled media. Abah's claims are valid insofar as the focus of social change remains outside of the operations of the ruling elite. They are also valid if political constructions are camouflaged in ways not easily decipherable by and objected to by the Censor's Board. The films examined in Abah's work permits such claims because they focus on women's rights, equality and justice, and not on situations brought on by a government's actions and inertia such as those depicted in Black November.

Although scholars have claimed that films, like other art forms, are able to enact social change because of their ability to heighten emotions, to communicate visually and their capacity to speak to the affective domains of viewers and 'spect-actors', social change cannot occur accidentally or by mere screenings. Miller (2008) supports this position in claiming that "[S]ocial change media aims to integrate itself into a discourse, raising questions, reframing arguments, suggesting new directions or additional resources, in short, providing a structuring frame for these larger civic sector conversations" (p. 833). By dramatising the conflict in the Niger Delta and demonstrating inhumane aspects of the conflict, Black November seems capable of putting pressure on the implicated parties, providing "additional resources" and speaking to power in myriad ways where more formalised processes of dialogue and debate 
have proved futile. The idea that films alone, particularly Black November, cannot orchestrate social change in the Delta was made clear by viewers during the discussions that followed each screening.

\section{Audience Reactions and Conditional Influence}

The FGDs were conducted using four key questions: satisfactory representation, change potential, most powerful scenes to incite action and promote social change, and alternative circulation avenues. The questions examined how viewers thought the salient issues in the conflicts were brought to the fore and how such activist representations might expedite a process of change. Similar responses were grouped together to avoid reporting repetitive reactions. The first question was on how satisfactorily Black November addressed the key issues of the Niger Delta which Saro-Wiwa fought non-violently against and which Amata portrayed in his film. Rather than limit audience responses to three pre-determined categories, the author agrees with Staiger (2001), who goes beyond Hall's preferred, oppositional and negotiated readings, to describe the processes of interpretation because richer descriptions are obtainable that way (p. 284).

The question of satisfactory representation is based on the assumption that for change to be possible, a change which is an outcome of a filmmaker's effort, the film has to engage with the conflict or conversations so as to make the need for change evident, desirous and achievable. The discussion of this question was taken up from different perspectives provided by viewers, who chuckled, jeered, sniffed and gasped at different moments during the film screening. The fact that representations are often contentious with audiences claiming inaccurate portrayals of people and places featured prominently in the conversations. Barber's (1997) assertion that "changes in the ways of being an audience can also be described in terms of the technology of communication" (p. 347) and what that medium makes possible is pertinent to these discussions. Whether or not audiences recognise the limitations of the audio-visual platform in its representational mode proved irrelevant to their reception of the film. They expected to see the Niger Delta realities that are so familiar to them. Audiences explained their perceptions of presences and silences throughout the discussions. At least two people in each screening questioned the imbalance of perspectives presented by the filmmaker. One viewer said that accuracy of details and locations is as important as telling the story itself because inaccurate details distract a viewer, "making him focus on trivialities rather than on the big issues" (personal communication, November 2015).

As Hall (1999) observes, representations create awareness in ways envisioned by the filmmaker, but they do little in determining what the audience will make of the images portrayed. Expressions like, [the film] 'throws light on', 'highlights', 'foregrounds', 'shows to some extent' and 'creates awareness' were used by the audience to show how satisfactorily Amata's representational strategies engaged with the key problems of the Niger Delta region. These reflect a reading of the film by Nigerians, most of whom are enlightened about the 
Niger Delta through mainstream media. The viewers noted that much of their education about the Niger Delta problems were from local newspapers, foreign news media and documentaries, and more recently, online news platforms.

Some viewers' comments are expressed as follows (the initials denote the viewer):

OE: it addresses one significant problem that is the greed and corruption of the locals and government, which oil companies take maximum advantage of

KE: Yes, [the film] highlights the key issues in the area. It is a difficult situation with violence leading to violence. The problems are capitalist attitude of the Western Oil Companies, mercenary attitude of the chiefs, uncontrolled grief leading to violence in the Niger Delta...

OA: [This film] highlights devastating effects of multinational oil companies' operations. Foregrounds challenges faced by locals to overcome immediate crises

FW: The film shows the Niger Delta ravaged by exploitation of its ecosystem and people over the years by oil companies... [it also shows] Militancy

FO: human suffering and tragedy are well addressed; environmental degradation - not much done here, need for development of the area, not much either

IA: yes, highlighted environmental exploitation, causes of militancy and underdevelopment, cases of deceit, cheating and sabotage

Viewers were willing to voice their opinions on the problems laid out in the film. Among them, there were varying degrees of satisfaction, which reflected how deeply the problems were presented in the film. Miller (2008) observes that “[T]he acknowledgement of film's capacity to shape public will and consciousness has led to ... the visibility of fiction films directly and deliberately addressing human rights concerns" (p. 832). Unsurprisingly, filmmakers use the medium to great advantage, thus resulting in an increase in the production of films that deal with social change. But the depth of treatment of political issues in Nigerian films is arguably overlooked by the general public. Miller also points out that "this recent increase [of film's capacity to shape public consciousness] raises the need to examine the medium's particular assets and liabilities, and to explore the extent to which film can induce policy change and action" (ibid). The 90-minute film manages quite well to condense the struggles and life stories of thousands of people sufficiently to generate debate and social action. Only one comment hinted at the oil companies' plight in the area, "to an extent, it does...highlight the challenges... [and] problems faced by both the oil company and the people of the Niger Delta" This lone comment summarises the perspectives of all the characters involved in the conflict. Whereas other comments focus on the problems created by the oil company and the Nigerian government, this recognises the problems confronting Western Oil, which were hardly discussed in the FGDs. 
Obviously, not all viewers shared the sentiments that the film had done enough to portray some of the burning issues which Saro-Wiwa fought for and which his death evoked. Notable among such views, which were mostly made by Niger Delta indigenes, are general comments like the film left out details of the conflict, not enough was shown on environmental degradation, no government efforts to address the issues were shown. Some viewers were severely critical of the filmmaker, doubting the genuineness of his intentions and accusing him of pandering to Western filmmaking preferences. One viewer said, Amata wanted to get funds from abroad to make more films so he made this amateurish thing and he succeeded in getting the money, didn't he? Such criticism is of interest since it is reminiscent of those made of Saro-Wiwa during and after his lifetime. In spite of Saro-Wiwa's popularity and the global attention which his execution drew to human rights abuses, some would question the authenticity of his objectives. Igoni Barret, a Nigerian writer, wrote that "[E]ven in the Niger Delta, the theatre of Saro-Wiwa's labours as a writer and environmentalist, there is no consensus on the purity of his actions in the struggle that cost his life" (Barret, 2015).

More specific comments about dissatisfaction with the representation of the Niger Delta conflicts include:

JE: no, [the film] did not address ND problems satisfactorily, it left out education, environmental degradation, culture

FC: film does not go into details with regards to the environmental disasters but perhaps can't be helped

CY: it addresses some of the issues but I'm not sure it does so satisfactorily - social, health, educational issues were all ignored

IK: no, I don't think so. How can it? The chiefs and elders are egoistic, not thinking of the development of the people. The militants were for the people at the initial stage, but presently, they are seeking their personal benefit. But is that all that is happening there?

II: it did reasonably although there are a few other issues that may be pointed out

In the light of these responses and linking them to other questions discussed after the screening, one viewer asked, 'how can there be change if the film does not provide a deeper knowledge of the issues to be changed and how the change will occur?' This comment tied in with those that follow and led to the formulation of what I refer to as Conditional Influence.

Conditional Influence emerged from the discussions of the second question, where viewers identified the possibility (or not) of the film influencing change and policy-making at all levels of government, but only if certain conditions are met. Viewers provided a list of conditions upon which Black November might induce demonstrable social change in the Niger Delta. Some of those conditions are: if the right people see it, if the real issues are not trivialised the way Amata has done, if distribution is more diverse, if TV stations within and outside Nigeria air the film without focusing on the financial benefits to be derived from 
doing so, if the policy makers are honest, just and dedicated to their duty, if it is shown all over the world and used as an educational tool to depict the plight of the Niger Delta people, if the film was allowed to remain in the cinemas at home and abroad for longer periods, if the corruption represented in the film is checked since it is now well known. The series of 'ifs' that trailed the conversations around the potential impact of the film support the argument that Black November alone, while holding a change potential, is not an isolated change agent. Exceptions to the conditional views were fewer, and are summarised in the strongest of them. For example, one viewer submitted, "yes, it $x$-rayed the pains and agony that oil exploration inflicted on the people from this region. Hence, it can help government at all levels to form good policy to address these problems." An outright rejection of the remotest possibility of change through the film was also made in a passionate voice "a country like Nigeria where people in positions of power are often disconnected from the people, the potential is nonexistent". The speaker went on to cite examples in support of his claims, and to persuade other participants to agree with him.

A third sub-question dealt with scenes in the film that would instigate action or expedite the process of social change, were it in the viewers' power to do so. According to Shank (2004), "advocates working in environments that are dominated by cognitive and competitive rationalities may benefit by experimenting to find which art form - movement arts, literary arts, dramatic arts, or visual arts - will resurrect the playful, less judgmental, intuitive self in a person who has wedged the emotional, arts-based rationalities deep into forgotten crevices" (p.539). Thus, as emotional triggers, scenes in Black November can be used to access specific emotions or "unlock emotional barriers" (ibid.) which might induce thought and consequently, result in positive behavioural modification. The question was deliberately inserted to pin down exact triggers for change given an exposure to the film. The most recurring scene was the pipeline explosion that killed Ebiere's family followed by that in which dead fish caused by oil spillage was seen floating in the river. Again, similar responses were collated to avoid repetitions:

BR: gas harvest/explosion scene. Tear-jerking scenes undermines the raw gravity of the situations

CA: death of Ebiere's mother. Running to get some fuel and dying in the process as a result of the explosion

IK: The explosion at the beginning. Water: for restroom and drinking!!! Frustration at the dead fish. Nothing would stop me - the human tragedy is too brutal

JR: part where the stream of dead fishes was shown as a result of oil spillage. This shows clearly that they really lose on all sides, no clean water, no food, infertile land. Many lives were also affected

JE: the dying fish 
OE: all parts of the film would hasten my actions...we saw the environmental degradation, the way the people lived without basic amenities, the dead fish - the world knows the story of Exxon Valdez and Amoco Cadiz. The efforts at restoring the environment, the amounts paid out and ...in the ND, the world is silent

FW: The scenes about the burst pipeline and the one with the floating, dying fish. I would want to do something to keep the environment friendly and safe

PE: the explosion which killed over a thousand people is enough reason. However, the havoc caused by the spillage on the land and water is something to note. However, on the other hand, law must not be taken into the hands of individuals/groups other than the government

FO: spillage scenes and dead sea life (fishes)

II: the resilience and concern of Ebiere to bring positive change and resolution through peaceful dialogue is a motivating factor

BE: the part where thousands were blown up by explosion

According to Barber (1997), "the best reason for studying audiences is that they have a hand in the constitution of the meaning of a performance, text or utterance" (p. 356). Audiences provide interpretations that are not immediately evident from the film, but which are constructed by their social conditions and frames of reference. Responses to the third question point to the fact that the film did strike a positive chord for action, even if it failed to realise that action. It confirms Shank's (2004) position on films acting as powerful emotional triggers, which deliver behavioural change. The explosion scene caused viewers to gasp and exclaim in horror while the dead fish scene brought moans and hisses at the waste during all the screenings. Discussing this question generated the longest and most heated debates. Even though some viewers were of the opinion that the film did not satisfactorily deal with the key issues that plague the region as reported above, there was unanimity among the majority in pointing out the effects of those two scenes on them, and consequently, in recognising the potential impact the scenes held for enacting social change. Viewers revealed the film's inability to adequately dramatise the problems plaguing the region. However, the scenes spelt out above were sufficient, within the entire 90-minute screen time, to achieve what Yousman (2013) wrote of the respondents in his study despite occasional disagreements with television representations of inmates,

Viewers are thus positioned to accept that the program provides a 'real' peek behind the scenes in a maximum-security prison. Many of the respondents seemed to accept this even when they were shown scenes of repeated acts of outrageous and bizarre violence" (p. 204).

\section{It touched a nerve, but does if offer social change?}


Miller (2008) observes that "film's puissance lies in the extent to which it can alter individual opinion on a grand enough scale to incite changes of policy" (p. 833). In documenting the responses from the audience during the FGD, an attempt is made to reflect the sentiments and utterances of the viewers as production and re-consumption (Barber, 1997). Barber's argument in favour of reception as re-producing narratives is germane because viewing Black November allows for the internalisation of the cinematic world as well as the reminiscing of previously-forgotten personal trauma. Machor and Goldstein (2001) point out that the reception experience depends to a large extent on the specific and peculiar interpretive formations that viewers possess. In fact, the parallels between Black November and SaroWiwa's story was first drawn by audiences who are familiar with the life of the activist, and who by interest or ethnic affinity, keep abreast with the Delta conflict. Reception, Machor and Goldstein argue, is "culturally activated within specific contexts and local histories" (p. 205). These histories, either communal or individual, constitute the repertoire from which textual meaning is drawn. At different points in the film, (violent scenes of soldiers clubbing civilians, at the explosion that killed Ebiere's mother and brothers referred to above), there were gasps of horror, emotions of anger, brief laughter (when one of the chiefs fanned himself upon receiving the news of the bribe money he was to be illegally paid), tears (at the killings and burials), and recalling of private trauma similar to those depicted. At least five viewers from each FGD affirmed that the film made them recall their past similar occurrences in ways that took them out of the film and cast them into personal and communal histories of deprivation, hurt and loss.

FW: At a point, I stopped watching and started completing the film with my own story and stories of my relatives

KE: The film is too close to me, too close to home. I cried so much and because of that I can't watch the film again. It made me remember my childhood and all the bad things my family suffered...

TA: You can't show this film in any part of the Niger Delta. It's too dangerous. It will re-open wounds

FO: I can forgive you for showing this film because I'm in Lagos. Back home, I won't because it will hurt my people badly.

IE: You may not come back alive if you take this film to Asaba or even Ogoniland

The film's prospects of social change in the form of conflict resolution received a resounding and consensual no. It heightened negative emotions of people from the affected areas particularly because as they claimed, the film ended tragically with Ebiere's death by hanging. It re-opened wounds which they preferred to forget or deal with in more hopeful ways. The non-Niger Delta indigenes spoke more freely, calling for films that depict hope and future solutions to the problems just encountered in the film. One of the viewers said the film made him feel sick while another recalled the environmental disaster in words similar to what Ken Saro-Wiwa's son said on his father's 20th anniversary, 
People are still very angry and emotional about the issues. The mistrust is very deep-seated. We see the global awareness of my father and Ogoniland, but that is little consolation to the communities still drinking water with 900 times the World Health Organisation accepted level of (cancer-causing) benzene (Vidal, 2015, para 8).

The final question on alternative circulation avenues was prompted by the fact that while making a film about conflict is important for raising awareness around complex issues like the Niger Delta conflict, distributing the film widely is even more important. As stated earlier, there were more women than men in the audience. Only two women saw Black November when it was released in 2012. Others claimed that they had no idea that such a film existed. The discussions delivered echoes of distribution among wider networks and groups of citizens, especially those capable of changing policies and creating the desired social change. Viewers were of the opinion that all governmental agencies, whether relevant to the Niger Delta operations or not, should see the film. The clamour for alternative circulation and distribution avenues grew even louder at the mention of Non Governmental Organisations and media institutions. Because the film was not distributed widely in Nigeria, some viewers believed that with the right exposure, and to strategically-positioned citizens, it held huge prospects for change. This supports Abah's (2009) argument that Nigerian films are capable of generating change; however, such societal changes as seen in the discussions above, through the eyes of select viewers have yet to be actualised. Additional steps are required for actualisation.

\section{Conclusion}

This study was carried out on the 20th anniversary of Ken Saro-Wiwa's death, partly because the media was awash with commemorative articles and memorabilia of the human rights activist's life. November 2015 was arguably a kind of national reflection on the Niger Delta conflicts and the emerging narratives about social change from stakeholders in the oilproducing communities. Black November proved to be an incredibly apt alternative media form to investigate how nonpartisan viewers reacted to the issues at stake.

The audiences interrogated in this study produced narratives of their own as part of their interpretive strategies thus, attesting to Barber's and Hall's references to production and reception occurring as two distinct and autonomous activities. If Hall is right about decoding happening autonomously from encoding, then audiences' reading of Black November's (in)visible impact assumes full relevance and enables social meanings meet with the fictional world of the video film in a fluid fashion (Okome, 2007 p. 6). These readings are then reformulated into an "unending spiral of other social" (ibid.) and cultural texts. Like previous audience studies reflected on above, this paper asserts that the activity and creativity of audiences is at once objective and subjective. As Barber states, "changes in the ways of being an audience can be related to changes in the institutionalisation and economics of entertainment" (p. 347). Arguably, such economic changes tend to elicit objective responses 
from audiences who respond to Black November's production values, setting, casting and its 'success' in subverting the official mechanisms of minority rights violations. A comment such as 'this is a not only a Niger Delta story', but also a national and global one about and for people whose interests are systematically excluded reveals an active audience. This audience is mindful of state oppression all over the world, and uses the filmic images before it to read meanings into the global order and vice versa. When Krings and Okome (2013) describe Nollywood's reception as being informed by their similarity to audiences' "local cultural formations" as well as their "alterity" (p. 4), they refer to the objective and subjective perceptions of reading film texts which are bound to vary by contexts of production, institution and even viewing locations.

Evidently, one film alone, and particularly a feature film, is unable to effect the sort of lasting change sought in the Delta communities. But it contributes to the important conversations for instituting social change, the elimination of environmental injustice, the reversal of "slow violence" (Nixon, 2011) and the attainment of the "moral victory" that Saro-Wiwa penned in his last letter to William Boyd. It is a conversation without which the desired change will remain unattainable if perceptible to far-flung audiences. Black November serves the laudable albeit restricted purpose of raising awareness of the minority rights violations occurring within Niger Delta communities. But as the responses from audiences indicate, producing the film is but one of the many steps required to achieve its activist project. It has to be accompanied with documents, its release being well-timed and strategically distributed in order to elicit the desired change - that is the point of designing and launching a pre- and post-production social impact strategy. Some viewers even argued that if the film was presented as a documentary, rather than a fiction film, it would have served the cause of change better and more effectively. While that proposes a different research agenda, it is useful to argue that given Miller's (2008) and other scholars comments on scaling up exposure as well as the viewers' reactions, Black November holds as much potential as other media to rediscover social change. Strategic production and circulation are important to promoting change, as Shank and Schirch (2008) effectively argue,

By strategic, the authors mean that arts-based methodologies be conceptually grounded, coordinated with other forms of peace building approaches, infused with a long-term perspective vis-à-vis the nature of social change, and serious about evaluating their effectiveness and impact (p. 218).

As has been demonstrated in this paper, reception studies are scarce, yet they yield richer perspectives in revealing the effects of screen media in their contexts of production and consumption/re-consumption (Barber). Reception studies extend well beyond the politics of representation, which Nollywood scholars have been engaged with for nearly two decades, to what Milton (2015), writing in a different context on the dynamics of researching media representations, refers to as the "politics of impact" (p. 166). The contributions of this paper allow researchers to continue probing, through audience ethnographies, the meaning-making strategies that audiences draw on during and after viewing popular films. It also responds to the film and social change discourse giving it the unique perspective of audience perceptions, 
thus echoing the importance of the audience in ways eloquently acclaimed by Barber, Okome, Yousman and other scholars.

\section{References}

Abah, A. L. 2009. Popular culture and social change in Africa: the case of the Nigerian video industry. Media Culture Society 31(731), DOI: 10.1177/0163443709339456

Agina, A. 2013. The Niger Delta in Nigerian video films, Critical African Studies, 5(2), 79-91, DOI: 10.1080/21681392.2013.815054

Barret, I. 'We all stand before history':Remembering Ken Saro-Wiwa, the Nigerian writer and environmental activist on the 20th anniversary of his execution. Retrieved from http://www.aljazeera.com/indepth/features/2015/11/stand-history151110063249816.html on November 10, 2015

Boyd, W. 1995. Introduction. In K. Saro-Wiwa. A month and a day: A detention diary. London: Penguin

Chinyowa, K. C. 2012. Building critical citizenship through syncretic theatre: A Zimbabwean case study, Journal of Peacebuilding \& Development, 7(2), 67-78, DOI: 10.1080/15423166.2012.743816

Hall, S. 1999. Encoding and Decoding in Television Discourse. In S. During, Ed. The cultural studies reader 2nd Ed., 507 - 517. London: Routledge

Haynes, J. 2013. The Nollywood Diaspora: A Nigerian video genre. In M. Krings and O. Okome 2013. Global Nollywood: The transnational dimensions of an African video film industry. 73 - 99. Bloomington: Indiana University Press

Krings, M. 2010. The localization of Nigerian video films in Tanzania. In M. Saul and R. A. Austen, eds. Viewing African cinema in the twenty-first century: Art films and the Nollywood video revolution, 74 - 91. Athens, OH: Ohio University Press

Krings, M. and O. Okome. 2013. Global Nollywood: The transnational dimensions of an African video film industry. Bloomington: Indiana University Press

Lederach, J. P. 2005. The moral imagination. Oxford, MA: Oxford University Press 
Machor, J. L. and P. Goldstein. 2001. Reception study: From literary theory to cultural studies. New York: Routledge

McCall, J. C. 2007. The pan-Africanism we have: Nollywood's invention of Africa. Film International, 28: 92 - 97

Miller, N. 2008. Projecting hope and making reel change in Africa. Human Rights Quarterly. 30(3): 827 - 838, DOI: 10.1353/hrq.0.0029

Milton, V. C. 2015. Media research: So what difference does it make? African Journalism Studies, 36(1): 163-168, DOI: 10.1080/23743670.2015.1008185

Morley, D. 2001. Unanswered questions in audience research. E-compos, 1-25

Nixon, R. 2011. Slow violence and the environmentalism of the poor. Cambridge MA: Harvard University Press

Obibesan, A. 2015. Pardon call as anniversary of Saro-Wiwa's death marked in Nigeria. Retrieved from http://www.timeslive.co.za/africa/2015/11/10/Pardon-call-asanniversary-of-Saro-Wiwas-death-marked-in-Nigeria on December 4, 2016

Okome, O. 2007. Nollywood: Spectatorship, Audience and the Sites of Consumption Postcolonial Text, 3(2): 1-21

Schroder, K., K. Drotner, S. Kline, C. Murray. 2003. Researching audiences. New York: Oxford University Press Inc. Arnold Publishers

Shank, M. 2004. Redefining the movement: Art activism. Seattle Journal for Social Justice. 3(2): 531 - 559

Shank, M. and L. Schirch. 2008. Strategic arts-based peacebuilding. Peace and Change (33)2: $217-242$

Staiger, J. 2001. Media reception studies. New York: New York University Press

Vidal, J. 2015. Protest threatened over memorial 20 years after Ken Saro-Wiwa execution. Retrieved from https://www.theguardian.com/world/2015/nov/07/ken-saro-wiwaogoni-people-shell-anniversary-memorial-bus on November 2, 2016

Yousman, B. 2013. Revisiting Hall's Encoding/Decoding Model: Ex-Prisoners Respond to Television Representations of Incarceration, Review of Education, Pedagogy, and Cultural Studies, 35(3): 197-216, DOI: 10.1080/10714413.2013.803340 